\title{
Overweight and obesity among children: Assessment of associated factors in a hospital sample from Gampaha
}

Vishnukumar $\mathrm{S}^{1}$, Liyanage $\mathrm{PN}^{2}$, Sivakanesan $\mathrm{R}^{3}$

Key words: Childhood Obesity, Overweight, Hypertention

\section{Abstract}

Background: Childhood obesity is one of the most serious public health challenges of the $21^{\text {st }}$ century. Overweight and obese children are at higher risk for developing long-term chronic diseases. With globalization and changing lifestyles, adolescents are exposed to multiple risk factors apart from hereditary risk factors. Obesity and overweight are two such risk factors, early diagnosis which are important to prevent complications associated with them.

Objective: To determine the prevalence and associated factors of childhood overweight and obesity among children 5-15 year of age group and to describe certain socio - demographic characteristics related to overweight and obese children.

Material and Methods: A Descriptive cross-sectional study was conducted among 5-15-year-old children from Gampaha District who attended the Nutritional Clinic and Pediatric Unit between December 2015 and June 2016. Those who had Body Mass Index (BMI) above $85^{\text {th }}$ centile for age and gender were included to the study. Children with any chronic illness were excluded from the study.

Results: A total of 116 children were included. The prevalence rates of overweight and obesity were $75.5 \%$ and $21.8 \%$ respectively. Prevalence of central obesity was more in female than male. Waist-hip ratio (WHR) and waist height ratio ( $\mathrm{WHtR}$ ) exhibited an age-dependent decrease for both genders. $23.2 \%$ of overweight and $28.6 \%$ obese children were found to have either their systolic BP (SBP) or diastolic BP (DBP) more than $95^{\text {th }}$ percentile.

Conclusion: Overweight/obesity was found to be moderately prevalent in this study. There was strong a association with hypertension, Timely identification and

1. Lecturer in Paediatrics, Faculty of Healthcare Sciences, Eastern University, Sri Lanka

2. Consultant Pediatrician, District General Hospital, Matara

3. Senior Professor, Department of Biochemistry, Faculty of Medicine, University of Peradeniya

https://orcid.org/0000-0003-3320-6016 control of overweight/obesity is required for prevention of development of adverse health outcome associated with these risk factors.

Keywords: Children, Hypertension, Obesity, Overweight,

\section{Introduction}

According to World Health organization, obesity is defined as being at or above the $95^{\text {th }}$ percentile of Body Mass Index (BMI) for age and sex and overweight as being between the $85^{\text {th }}$ and $95^{\text {th }}$ percentiles of BMI for age and sex. WHO defines $\mathrm{BMI}$ as being weight in kilogram per height in square meters and recommends for use in children and adolescents. ${ }^{1}$ WHO has named obesity as a 'Global Epidemic'. Traditionally, overweight/obesity used to be considered a problem in developed countries. However this problem has been on the rise in developing countries, particularly in urban areas due to change in lifestyles and food habits. ${ }^{2,}$ ${ }^{3}$ Distribution of body fat is an additional important determinant in predicting the future cardiovascular risk factors. Although the BMI is the commonly used tool in diagnosing overweight and obesity, waist circumference (WC) percentile and waist height ratio (WHtR) demonstrated high sensitivity and specificity for detection of abdominal fat mass.

Globally childhood obesity has increased from $4 \%$ in 1990 to $6 \%$ in 2010, and is expected more to increase to $9 \%$ or approximately 60 million affected by $2020 .{ }^{4}$ In recent years, the increase in the prevalence of obesity especially among children, has led this condition to the forefront of the public health discussion in Sri Lanka. The overweight and obesity prevalence among children in Sri Lanka shows provincial and gender differences. Among 8 and 10 year age group in 2008 in Colombo district, obesity rate was $4.3 \%$ for boys and $3.1 \%$ for girls. Obesity prevalence among primary school children was $5.1 \%$. In 2013 the prevalence of overweight/ obesity was about $13 \%$ among urban children, aged 5-15, in Sri Lanka. ${ }^{5}$ An islandwide survey carried out in 2001 revealed the prevalence of overweight and obesity in Gampaha area as 6.5\% and 2.0\% respectively. ${ }^{6}$ 
Objectives of this was study was

1. To assess the risk factors of overweight and obesity among children aged from $5-15$ years who visited District General Hospital Gampaha.

2. To describe socio - demographic characteristics related to overweight and obesity among those children.

\section{Methodology}

This study was a hospital based descriptive study among children aged 5-15 years from Gampaha District. All children aged 5-15 who visited the Nutritional clinic and Pediatric Unit between December 2015 and June 2016 were enrolled into the study. Age was verified from parents / guardians and with their date of birth and rounded off to completed years Height was measured by using stadiometer with child standing upright barefoot on ground with heels, buttocks touching wall and head in the Frankfurt plane. A calibrated and standardized electronic weighing scale was used to measure weight. $\mathrm{BMI}$ was calculated using the formula $\mathrm{BMI}=$ weight in $\mathrm{kg}$ / (height in meter) ${ }^{2}$.

Hip circumference $(\mathrm{HC})$ and Waist circumference (WC) were measured twice using inextensible anthropometric tape with the child standing erect and relaxed with arms at the sides and feet positioned close together. Waist circumference was measured midway between the lowest border of rib cage and the upper border of iliac crest, at the end of normal expiration. Waist-hip ratio (WHR) was calculated by WC/HC. Blood Pressure (BP) was measured by Multi-Para monitor using appropriate sized cuff.

A child was classified according to U.S Centre for Disease Control and Prevention/National Centre for Health Statistics (CDC/NCHS) guidelines as overweight with BMI for age and sex between $85^{\text {th }}$ and $95^{\text {th }}$ percentiles and as obese with BMI for age and sex at or above the $95^{\text {th }}$ percentile. To obtain information from the parents were obtained from a questionnaire.

Ethical approval for the study was obtained from the Ethical Clearance Committee of the Post Graduate Institute of Medicine (PGIM), University of Colombo, Sri Lanka.

Data analysis was done using SPSS 20.0 (SPSS Inc, Chicago, IL).

\section{Results}

Socio-demographic details of the participants are in Table 1 below.
Table1: Sociodemographic data of the participants

\begin{tabular}{|c|l|l|}
\hline Category & $\begin{array}{l}\text { Frequency } \\
\text { (f) }\end{array}$ & $\begin{array}{l}\text { Percentage } \\
\text { (\%) }\end{array}$ \\
\hline $\begin{array}{c}\text { Mender } \\
\text { Female }\end{array}$ & 56 & 48 \\
\hline Age & 60 & 52 \\
0-5 years & 5 & \\
6-9 years & 45 & 49 \\
$10-12$ years & 39 & 34 \\
$>15$ years & 27 & 23 \\
\hline Nationality & & \\
Sinhalese & 110 & 94.8 \\
Tamils & 01 & 0.8 \\
Muslims & 05 & 4.3 \\
\hline Family income (Rs) & & \\
$<25000$ & 24 & 21 \\
25000-50000 & 63 & 54 \\
$50000-75000$ & 14 & 11 \\
$>75000$ & 15 & 12 \\
\hline
\end{tabular}

The sample consisted of a total of 116 children. The mean age in the study was seen to be 11.8 years with standard deviation of 2.9. Age range was 5-15 years. Majority $(66.8 \%)$ of the participants were over 10 years. $48 \%$ were males. 110 (94.83\%) were Sinhalese with $0.8 \%$ and $4.3 \%$ constituting Tamil and Muslim ethnicities respectively.

Approximately $40 \%$ of mothers and fathers were educated up to GCE ordinary level of education and $4 \%$ of them had University level qualifications. $12 \%$ of mothers and $9 \%$ of fathers were educated only up to at primary level.

Nearly half of the participant's families (54\%) earned an income between Rs.25000-50000 and 23\% of them earned income above Rs.50000. Rest of the families income fell below Rs. 25000.

Around $29 \%$ of the participant children had been spending on average 1-3 hours per day on play activities. $18 \%$ of children have not been involved in any play. $53 \%$ children were involved in play activities but not on regular basis. During weekends children spend more time watching television. During the weekends about $55 \%$ children spend 1- 2 hours each day watching television. During weekdays majority children spend less time watching television. 
More than $64 \%$ of sample spent time on attending extra classes during weekdays and weekends Most of the participants $(55.0 \%)$ were having the family history of Diabetes Mellitus while $40 \%$ of them show the history of hypertension.

Mean height of the sample was $141 \mathrm{~cm}(S D=15.87)$ and mean weight was $35.99 \mathrm{~kg}(\mathrm{SD}=12.14)$. BMI was calculated and classified as per the WHO guidelines. It was seen that $75.5 \%$ of the respondents were obese and $21.8 \%$ of the respondents were overweight. Only $2.7 \%$ of the respondents were found to be having normal BMI.

Age was not significantly associated with overweight or obesity ( $p=0.363)$. Both males and females represented almost equal proportion in the overweight/obese category.

Table 3 shows the relationship between the overweight/ obesity and the hypertension. Hypertension in children and adolescents defined as systolic BP (SBP) and / or diastolic BP (DBP), on repeated measurement, $\geq 95$ th percentile for the age, sex and height. ' [ In this study $23.2 \%$ and $28.6 \%$ of overweight and obese children were found to have either their SBP or DBP more than $95^{\text {th }}$ percentile. The association of hypertension with overweight/obesity was statistically significant in our study $(p=0.001)$. However sex was not found to be significantly associated with hypertension (0.915).

Table 2 depicts the data on Body mass index.

Table 2: BMI classification of the Respondents ( $n=116)$

\begin{tabular}{|l|l|l|l|}
\hline BMI Category & Category & $\begin{array}{l}\text { Number } \\
(\mathrm{n})\end{array}$ & Percentage (\%) \\
\hline \multirow{3}{*}{ BMI category } & Normal & 3 & $2.7 \%$ \\
\cline { 2 - 4 } & Overweight & 25 & $21.8 \%$ \\
\cline { 2 - 4 } & Obese & 88 & $75.5 \%$ \\
\hline
\end{tabular}

Table 3: Association of BMI with hypertension $(n=116)$

\begin{tabular}{|l|l|l|l|l|}
\hline \multirow{2}{*}{$\begin{array}{l}\text { Risk } \\
\text { factors }\end{array}$} & \multirow{2}{*}{\begin{tabular}{l} 
Category \\
\cline { 3 - 4 }
\end{tabular}} & $\begin{array}{l}\text { Nood pressure } \\
(\%)\end{array}$ & $\begin{array}{l}\text { Hypertension } \\
(\%)\end{array}$ & P value \\
\hline \multirow{3}{*}{ BMI } & Normal & $94.5 \%$ & $5.5 \%$ & 0.001 \\
\cline { 2 - 4 } & Overweight & $76.8 \%$ & $23.2 \%$ & \\
\cline { 2 - 4 } & Obese & $71.4 \%$ & $28.6 \%$ & \\
\hline
\end{tabular}

BMI of children was found to have $77.7 \%$ sensitivity and $55.5 \%$ specificity to detect central obesity. The positive predictive value was $95.4 \%$ while the negative predictive value was $17.2 \%$. In this study $83.7 \%$ of actually overweight population lied in alert line (Figure 1 ) and $43.7 \%$ of actually obese population lied in action line (Figure 2).
Figure 1: $83.7 \%$ actually over weighted population lied between $\mathrm{W} / \mathrm{H}$ ratio $0.49-0.59$ (alert line)

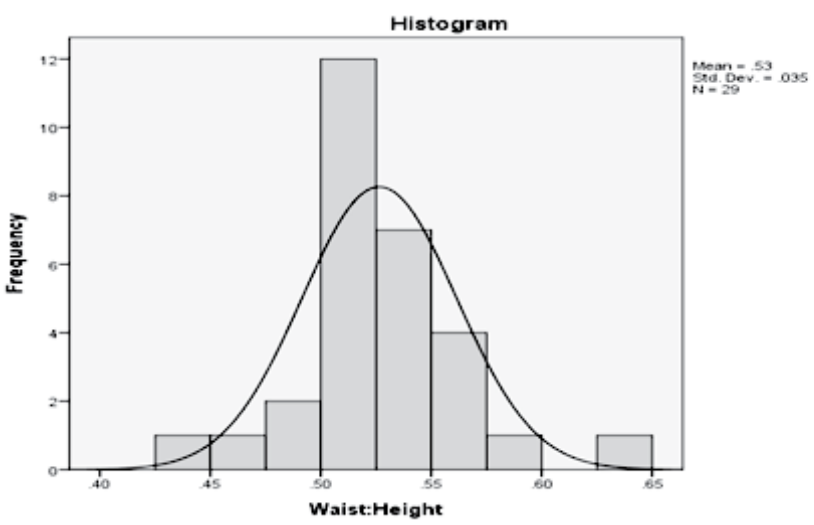

Figure 2: $43.7 \%$ actually obese population lied between $\mathrm{W} / \mathrm{H}$ ratio $>0.59$ (action line)

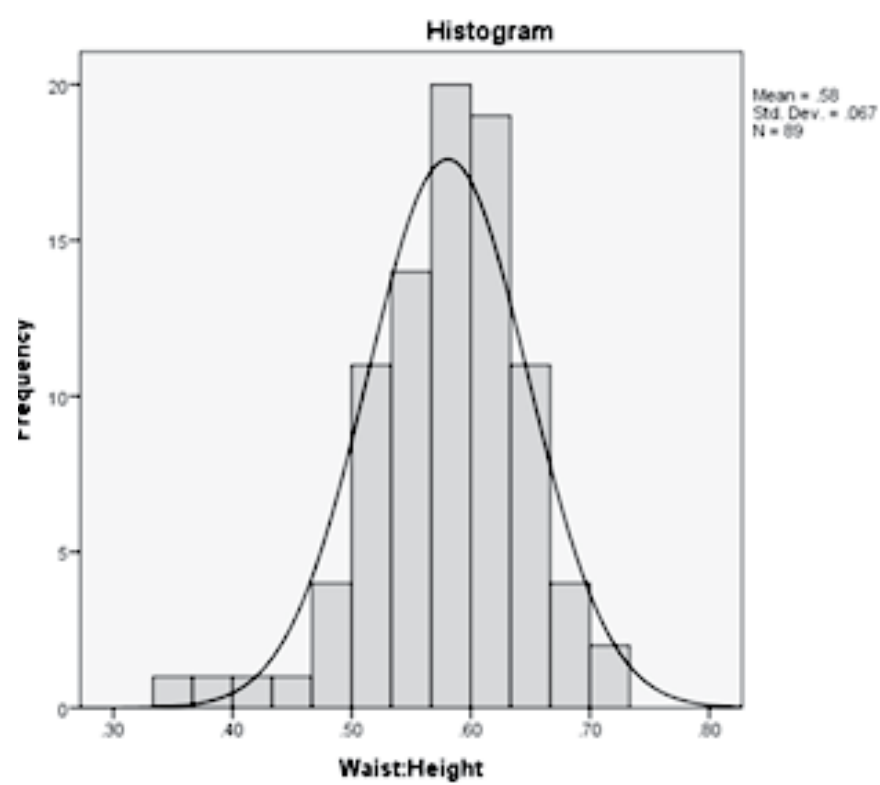

Mean BMI increased with age and $11.1 \%$ were found to have obese waist circumference (based on their $90^{\text {th }}$ percentile). The percentage of adolescents who exceeded the $90^{\text {th }}$ percentile reached a peak at the age of 13 years (averaging about 14\%) and showed a decrease at the age of 15 years (averaging about 8.6\%). Thus, the age group of 13 years appeared to be at increased risk for central obesity but this risk seemed to decrease after the age of attainment of peak height velocity.

WHR and WHtR exhibited an age-dependent decrease for both genders. The cut-off of WHR $>0.90$ corresponded at the $97^{\text {th }}$ WHR percentile for boys whereas the cut-off of $>0.85$ corresponded at the $93^{\text {rd }}-99^{\text {th }}$ percentiles in girls according to age. 


\section{Conclusion:}

The sample being a hospital sample, the different age range and definition criteria could partly explain the higher rate found in this study. However a true increase obesity rate in community over the years also could have contributed to this rate increase, clarification of which is beyond this study.

This study found a strong association between overweight and obesity with hypertension, calling for recommendations to screen for hypertension in overweight and obese children at all outpatient medical visits.

\section{Acknowledgements}

We would like to acknowledge the support of medical officers from obesity clinic, District General Hospital Gampaha and the children, families, and community members who made this research possible.

\section{References}

1. Huang TT, Glass TA, Transforming research strategies for understanding and preventing obesity, Jama. 300:15 (2008) 1811-3.

2. Gravett MG RC, Nunes TM, Global report on pretermbirth and stillbirth (2 of 7): discovery science, BMC pregnancy childbirth. 10 (2010) S2.
3. Population MoHa, Child Health Division [Nutrition Section], Kathmandu: National Nutrition Policyand Strategy. (2004).

4. De Onis M BsM, Borghi E, Global prevalence andtrends of overweight and obesity among preschool children, American Journal of Clinical Nutrition. 92 (2010) 1257-64.

5. P. Premarathne, A. De Silva and V.P.Wickramasinghe. Descriptive analysis of factors associated with overweight and obesity among children in urban Sri Lanka. Proceedings of the Peradeniya University. International Research Sessions, Sri Lanka, Vol. 18, $4^{\text {th }} \& 5^{\text {th }}$ July, 2014.

6. Piyasena.C and Mahamithawa AMASB. Assessment of anemia status in Sri Lanka, Medical Research Institute of the Department of Health Service, Sri Lanka 2003.

7. Falkner, B., Daniels, S. R., Flynn, J. T., Gidding, S., Green, L. A., Ingelfinger, J. R. \&Rocchini, A. P. The fourth report on the diagnosis, evaluation, and treatment of high blood pressure in children and adolescents. Pediatrics, 2004;114(2 III), 555-576 